\title{
Citrus Soil pH Testing Procedures ${ }^{1}$
}

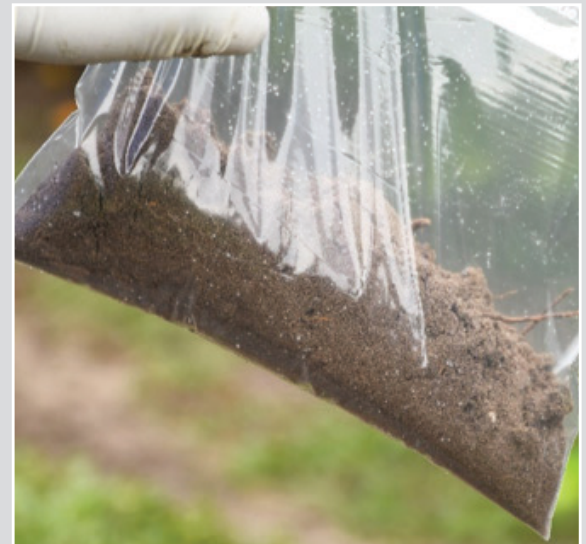

Collect soil sample. Credit: Tonya Weeks, UF/IFAS CREC

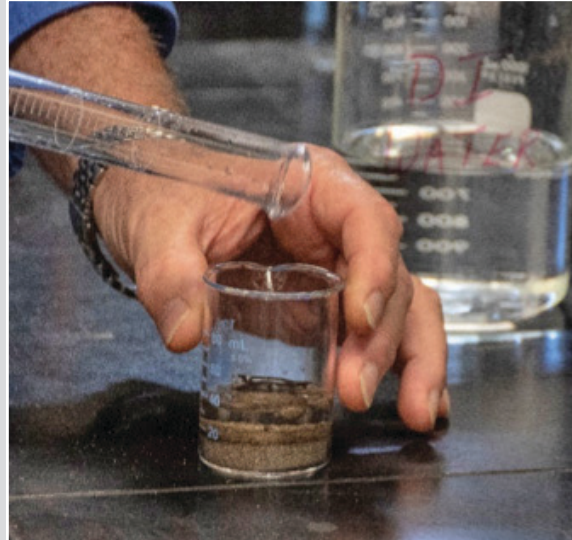

Mix soil and distilled water in a 1:1 ratio by volume.

Credit: Tonya Weeks, UF/IFAS CREC

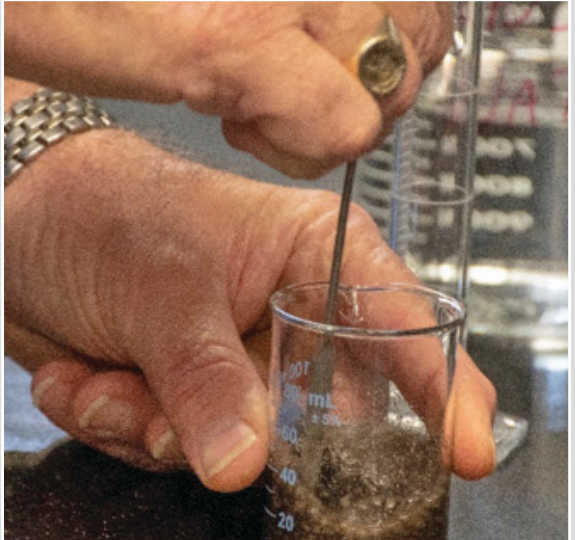

Continuously stir for 1 minute, then let stand for 15-30 minutes. Credit: Tonya Weeks, UF/IFAS CREC

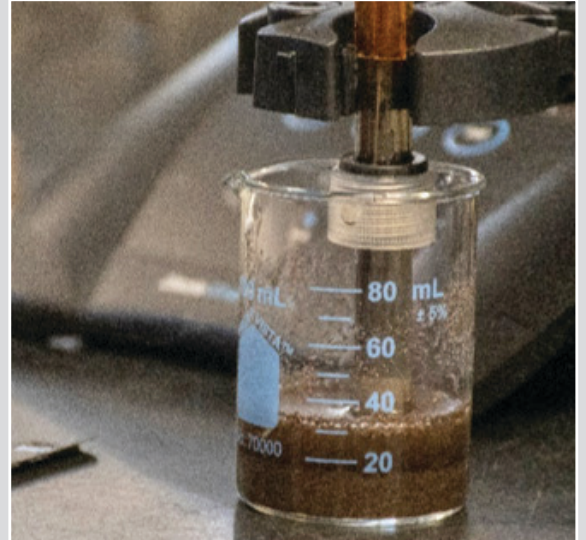

Use testing equipment to gather soil pH readings.

Credit: Tonya Weeks, UF/IFAS CREC

\section{Facts}

- Maintaining the correct soil pH is essential to ensure optimal plant growth and crop yield.

- Soil samples should be taken once per year, ideally at the end of the rainy season.

- It is generally convenient to take soil samples when collecting leaf samples.

- The accuracy of soil test interpretations depends on how well soil samples represent the area tested.

- The slurry method allows you to get a representative sample and measurement of an entire area with just one test.

\section{Soil Sample Method}

- Because soil pH can vary within a small area, be sure to take samples that are representative of the production block.

- Take several soil samples to a 6-inch depth from under 15 to 20 tree canopies (irrigation zone) into a bucket.

- Mix soil and place about one handful of soil in a sample bag marked with the sample location and date.

- Samples should also be taken from between tree rows (bed tops or row middles) using the procedure above.

- Keep these two samples separate.

\section{Soil pH Measurements}

- Temperature fluctuations will cause measurement errors, so samples should be analyzed as soon as possible.

- Add equal parts of soil and distilled or deionized (DI) water in a 1:1 ratio by volume.

- Continuously stir the suspension for at least 1 minute.

- Let the soil suspension stand for about 15-30 minutes to allow most of the suspended soil to settle out.

- If electronic testing equipment is used, the electrodes must be thoroughly rinsed with deionized or distilled water between samples.

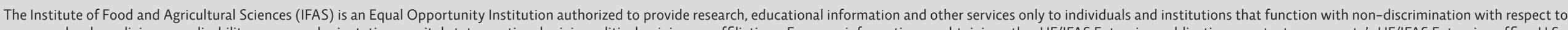

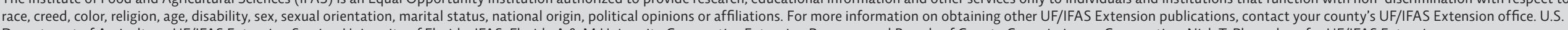
Department of Agriculture, UF/IFAS Extension Service, University of Florida, IFAS, Florida A \& M University Cooperative Extension Program, and Boards of County Commissioners Cooperating. Nick T. Place, dean for UF/IFAS Extension. 


\section{pH Testing Equipment}

\section{Test Strips}

- pH test strips, also known as litmus paper, are paper strips that have been saturated with $\mathrm{pH}$-sensitive dyes.

- When exposed to a damp substance, the strips will change color relative to that substance's $\mathrm{pH}$. This color change corresponds to a color chart provided with the test strips.

\section{ADVANTAGE}

- This method for testing is quick, easy, and inexpensive.

\section{DISADVANTAGE}

- Test strip results are subjective because colors can look different depending on the lighting as well as from person to person. This leads to inconsistent results (+/$0.5 \mathrm{pH}$ )

\section{Chemical Test Kits}

- $\mathrm{pH}$ chemical test kits are like test strips one would use to determine the $\mathrm{pH}$ of pool water.

- Using a soil test kit involves adding your soil, distilled or DI water, and some chemicals to a tube.

- The chemicals react with the $\mathrm{pH}$ levels in your sample to create a color change.

\section{ADVANTAGE}

- Test kits are easy to use.

\section{DISADVANTAGE}

- Readings depend on interpretation of color, which may vary for different people and are therefore subjective.

\section{Electronic Measurements}

- Each instrument/electrode system described below must be calibrated at a minimum of two points that bracket the expected $\mathrm{pH}$ of the samples and are approximately three $\mathrm{pH}$ units or more apart to obtain the best results.

\section{Digital Pocket Testers}

- Soil pH pocket testers are digital, portable testing instruments that utilize a $\mathrm{pH}$ electrode.

- The $\mathrm{pH}$ electrode takes a $\mathrm{pH}$ reading in your soil or soil slurry and displays it on an LCD screen.

- Many testers also have a much higher resolution and accuracy than chemical options, generally between 0.1 and $0.01 \mathrm{pH}$ units.

\section{ADVANTAGE}

- The integration of a pH electrode in the durable casing of a tester allows for much greater accuracy than test kits or strips.

\section{Portable Soil pH Meters}

- A bit larger than the digital pocket testers, portable soil $\mathrm{pH}$ meters offer many functions, including measuring salinity and data logging.

- Most portable pH meters have automatic temperature compensation; they will come with either an integrated temperature sensor or a separate temperature probe.

- Portable soil pH meter measurements have resolutions as low as $0.001 \mathrm{pH}$ units.

\section{ADVANTAGE}

- Portable pH meters are a convenient way to have laboratory accuracy in field testing.

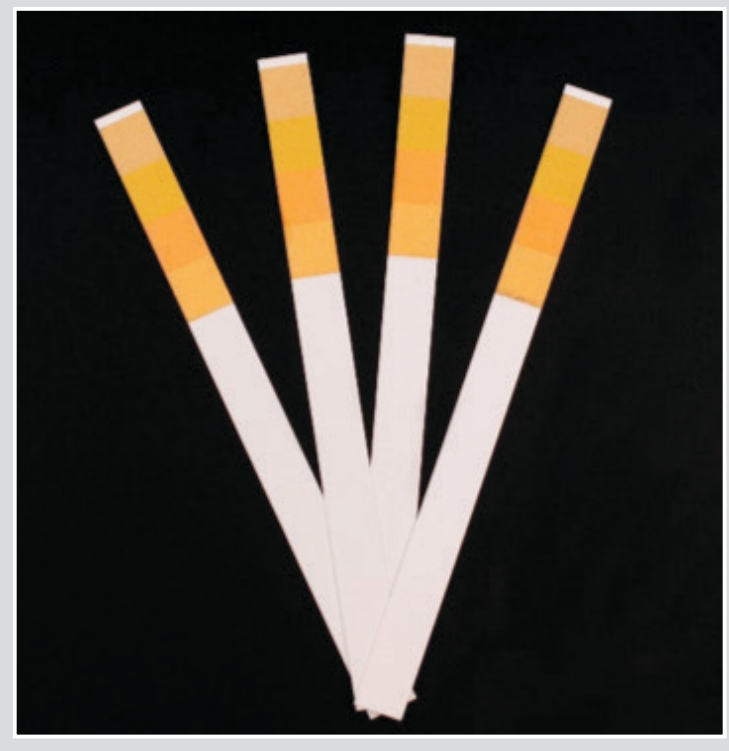

pH test strips.

Credit: Tonya Weeks, UF/IFAS CREC

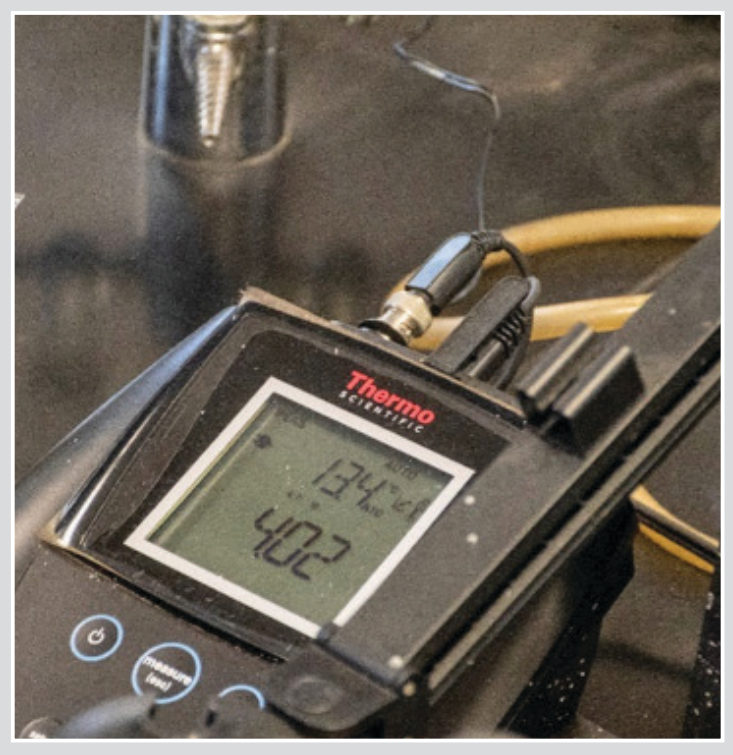

Electronic $\mathrm{pH}$ tester.

Credit: Tonya Weeks, UF/IFAS CREC 